\title{
Anemia in young children living in the Surinamese interior: the influence of age, nutritional status and ethnicity
}

\section{CWR Zijlmans'}

A Stuursma ${ }^{2}$

AJ Roelofs ${ }^{2}$

BC Jubitana ${ }^{3}$

MS MacDonald-Ottevanger'

'Department of Mother \& Child Health Care, Scientific Research Center Suriname, Academic Hospital Paramaribo, Paramaribo, Suriname; ${ }^{2}$ Faculty of Medicine, University Medical Center Groningen, Groningen, the Netherlands; ${ }^{3}$ Department of Monitoring Evaluation Surveillance \& Research, Medical Mission PHCS, Paramaribo, Suriname
Correspondence: CWR Zijlmans Scientific Research Center Suriname, Academic Hospital Paramaribo, Picornistraat II, Paramaribo, Suriname Email cwrzijlmans@ researchcentersuriname.org
This article was published in the following Dove Press journal:

Research and Reports in Tropical Medicine

22 February 2017

Number of times this article has been viewed

Purpose: This study investigates the prevalence of anemia in young children living in the interior of Suriname and the influence of the associated factors age, nutritional status and ethnicity. Patients and methods: In this cross-sectional observational study, 606 children aged 1-5 years from three different regions of Suriname's interior were included, and hemoglobin levels and anthropometric measurements were collected. Logistic regression models were computed to examine independent associations between anemic and nonanemic groups and to measure the influence of age, nutritional status and ethnicity.

Results: A total of 606 children were included, of whom 330 (55\%) were aged 1-3 years and 276 were aged $4-5$ years. The overall prevalence of anemia was $63 \%$. Younger age was associated with anemia (odds ratio $[\mathrm{OR}]=1.78 ; 95 \%$ confidence interval $[\mathrm{CI}]: 1.27-2.51$ ). Anemia was less prevalent in Amerindian than in Maroon children ( $\mathrm{OR}=0.51$; 95\% CI: 0.34-0.76). Hemoglobin level was not influenced by nutritional status nor by sex.

Conclusion: The prevalence of anemia in children aged 1-5 years living in Suriname's interior is high (63\%) compared to that in similar aged children in Latin America and the Caribbean (4-45\%). Children aged 1-3 years were more affected than those aged 4-5 years as were Maroon children compared to Amerindian children. Nutritional status and sex were not of influence.

Keywords: Maroon, Amerindian, hemoglobin, malnutrition, stunting, younger age

\section{Introduction}

Anemia is the world's second leading cause of disability and affects $43 \%$ of all children worldwide. ${ }^{1}$ Childhood anemia is often multicausal, with age, nutritional status, inflammation, infections and ethnicity - related to inherited conditions such as sickle cell disease and thalassemia - being significant contributors. Age is widely recognized as an important determining factor of anemia affecting primarily children under 2 years of age $^{2}$ and almost half of preschool children. ${ }^{3}$ Nutritional deficiencies play an important role in childhood anemia, iron deficiency being the most common cause. ${ }^{4}$ Children suffering from iron-deficiency anemia during their first 2 years of life have slower cognitive development and poorer school performance and work capacity later in life. ${ }^{5}$

The Republic of Suriname, situated on the north-eastern coast of South America, has a highly diverse society consisting of Hindustanis, Maroons, Creoles, Javanese, indigenous Amerindians, Brazilians, Chinese and individuals from mixed ethnicity. The majority of its half million inhabitants live in the northern coastal plain. The far greater part of the country's interior is covered by tropical rainforest and is inhabited primarily by Maroons and Amerindians. The World Bank reports an overall 39\% prevalence rate 
of anemia among children aged under 5 years in Suriname, ${ }^{6}$ however, little information is available on the prevalence of anemia in young children living in the interior. The Medical Mission Primary Health Care Suriname is responsible for health care in Suriname's interior and documents information on demographic and other factors of the interior population, e.g., age, sex, ethnicity, nutritional status and hemoglobin level. The prevalence rates of anemia and associated factors may vary in the different regions in Suriname's interior due to ethnic differences and nutritional and cultural habits.

The primary aim of this study is to determine the prevalence of anemia in children aged 1-5 years living in three different interior regions of Suriname. The secondary aim is to gain more insight into the relationship between the prevalence of anemia and the associated factors age, nutritional status and ethnicity. The outcome of this study may support adaptation of anemia prevention and control programs in young children in Suriname and in particular those of the Medical Mission.

\section{Patients and methods}

In this cross-sectional observational study, 606 children aged 1-5 years from three different regions of Suriname's interior were included in the period September-October 2015. Eligible study participants between 12 and 71 months of age who lived in or near the selected villages were invited to come to the local Medical Mission health post and included in the study by convenience sampling on a first-come, first-served basis. To facilitate parents who were unable to visit the health post, two trained investigators went into the villages under guidance of the Medical Mission staff to include children. Verbal assent was obtained from each child, and written informed consent was obtained from each child's parent or guardian after they were fully informed about the study in a language they could understand. The selection of these villages was based on urbanization, i.e., they were classified as urban or rural based on accessibility by road, availability of electricity and/or tap water, access to food stores and ethnicity: Brokopondo and Brownsweg are located in an urban area with a mainly Maroon population; Pikin Slee and Hekununu are remote rural villages far upstream only accessible by boat, and their population consists entirely of Maroons; and the urban Amerindian villages Apoera and Washabo are in West-Suriname.

Age, sex and ethnicity were recorded; weight and length were measured using a portable weight scale (HealthOMeter $^{\circledR}$; Seca, Chino, CA, USA) and a body length measurement instrument (Road $\operatorname{Rod}^{\circledR}$, Hopkins, Caledonia, MI,
USA), respectively. Anthropometric variables were computed using the World Health Organization (WHO) Child Growth Standards SPSS Syntax File for children 0-5 years of age and WHO Anthro (version 3.2.2, January 2011) and macros for SPSS and Igrowup for children 5-19 years of age (standard deviation, SD). ${ }^{7,8}$ Malnutrition was defined according to WHO standards as body mass index (BMI) $\leq 2 \mathrm{SD}$, and stunting was defined as height-for-age $z$-score $\leq 2 \mathrm{SD}$. Hemoglobin levels were drawn from every participant by a single finger prick and measured with a mobile device (Stat-Site ${ }^{\circledR}$ MHgb, Stanbio Laboratory, Boerne, TX, USA). For the 12-59 months age group, a blood hemoglobin level lower than the recommended WHO threshold of $11.0 \mathrm{~g} / \mathrm{dL}$ $(6.83 \mathrm{mmol} / \mathrm{L})$ was used as cut off point to identify anemia, and a cut off of $11.5 \mathrm{~g} / \mathrm{dL}(7.14 \mathrm{mmol} / \mathrm{L})$ was used for children older than 59 months.$^{9}$

Subjects were excluded in case of critical physical condition: children with severe anemia and unstable vital signs would immediately be referred for admission, treatment and diagnostic work-up to the Diakonessenhuis hospital in Paramaribo, the capital of Suriname. Children aged 12-47 months (1-3 years) were classified as very young children, and children aged $48-71$ months (4-5 years) were classified as older children.

For statistical analysis and power calculation, the Medical Mission-owned database was used, which contains information on all children living in the selected villages. A sample size of 603 was calculated to reach a power of $80 \%$, a $95 \%$ confidence interval (CI), with a 5\% margin of error. Descriptive, bi- and multivariable logistic regression analyses were applied to test differences in sex, age, ethnicity and nutritional status between the anemic and nonanemic groups. A $p$-value $<0.05$ was considered statistically significant. All analyses were performed using the Statistical Package for the Social Sciences (SPSS) version 22.0 for Windows (SPSS Inc., Chicago, IL, USA). The study was approved by the Commission of Human Subjects Research of Suriname's Ministry of Health (VG 019-15).

\section{Results}

A total of 606 children were included, of whom 330 (55\%) were very young (1-3 years) and 276 were older ( $4-5$ years) children, 315 (52\%) were males and 291 were females, and 471 (77.7\%), $131(21.6 \%)$ and $4(0.7 \%)$ were of Maroon, Amerindian and Mixed descent, respectively (Table 1).

Table 2 shows the population characteristics stratified for anemia and nonanemia. A total of $63 \%(n=381)$ were anemic, of which the majority $(60.1 \%, n=229)$ were in the $1-3$ years 
Table I Study population demographics and characteristics

\begin{tabular}{|c|c|c|}
\hline $\begin{array}{l}\text { Demographics and } \\
\text { characteristics }\end{array}$ & $n=606$ & $\%(95 \% \mathrm{Cl})$ \\
\hline \multicolumn{3}{|l|}{ Sex } \\
\hline Male & 315 & $52.0(48.0-55.9)$ \\
\hline Female & 291 & $48.0(44.0-52.0)$ \\
\hline \multicolumn{3}{|l|}{ Ethnicity } \\
\hline Maroon & $47 \mid$ & 77.7 (74.2-80.9) \\
\hline Amerindian & $|3|$ & $21.6(18.5-25.1)$ \\
\hline Mixed and others & 4 & $0.7(0.3-1.7)$ \\
\hline \multicolumn{3}{|l|}{ Region } \\
\hline Urban & 226 & $37.3(33.5-4 \mid .2)$ \\
\hline Rural & 380 & $62.7(58.8-66.5)$ \\
\hline Age (months)* & $43.7(46.5 ; 29.6-57.8)$ & \\
\hline Hemoglobin $(\mathrm{mmol} / \mathrm{L})^{*}$ & $6.6(6.6 ; 6.0-7.3)$ & \\
\hline Length $(\mathrm{cm})^{*}$ & $96.9(99.0 ; 86.9-107.0)$ & \\
\hline Weight $(\mathrm{kg})^{*}$ & $14.4(14.5 ; 11.7-17.0)$ & \\
\hline
\end{tabular}

Note: *Data reported as mean (median; interquartile range).

Abbreviation: $\mathrm{Cl}$, confidence interval.

Table 2 Population characteristics stratified for anemia and nonanemia; OR with $95 \% \mathrm{Cl}$.

\begin{tabular}{|c|c|c|c|c|}
\hline $\begin{array}{l}\text { Population } \\
\text { characteristics }\end{array}$ & $\begin{array}{l}\text { Non-anemia, } \\
n=225 \text { (\%) }\end{array}$ & $\begin{array}{l}\text { Anemia,* } \\
n=38 \text { I (\%) }\end{array}$ & $\begin{array}{l}\text { Bivariate, } \\
\text { OR }(95 \% \mathrm{CI})\end{array}$ & $P$-value \\
\hline Sex & & & & 0.73 \\
\hline Male & $119(37.8)$ & $196(62.2)$ & 1 & \\
\hline Female & $106(36.4)$ & $185(63.6)$ & I.06 (0.76-I.47) & \\
\hline Age group & & & & $<0.001$ \\
\hline I-3 years & I0I (30.6) & $229(69.4)$ & $1.85(1.33-2.58)$ & \\
\hline 4-5 years & $124(44.9)$ & $152(55.1)$ & 1 & \\
\hline Ethnic group & & & & $<0.001$ \\
\hline Maroon & $157(33.3)$ & $314(66.7)$ & I & \\
\hline Amerindian & $66(50.4)$ & $65(49.6)$ & $0.49(0.33-0.73)$ & \\
\hline $\begin{array}{l}\text { BMI** for age } \\
z \text {-score } \leq 2 S D\end{array}$ & & & & 0.11 \\
\hline No & $198(36.1)$ & $350(63.9)$ & 1 & \\
\hline Yes & $26(47.3)$ & $29(52.7)$ & $0.63(0.36-1.10)$ & \\
\hline $\begin{array}{l}\text { Height for age } \\
z \text {-score } \leq 2 S D\end{array}$ & & & & 0.05 \\
\hline No & 210 & $336(61.5)$ & 1 & \\
\hline Yes & $15(25.4)$ & $44(74.6)$ & $1.83(1.00-3.38)$ & \\
\hline Region & & & & 0.23 \\
\hline Urban & $77(34.1)$ & 149 (65.9) & 1 & \\
\hline Rural & | 48 (38.9) & $232(61.1)$ & $0.8 \mathrm{I}(0.57-\mathrm{I} .14)$ & \\
\hline
\end{tabular}

Notes: *Hemoglobin cutoff values for anemia according to $\mathrm{WHO}$ standards: children $<5$ years: $<6.83 \mathrm{mmol} / \mathrm{L}$ ( $<11.0 \mathrm{~g} / \mathrm{dL}$ ), $5-12$ years old: $<7.14 \mathrm{mmol} / \mathrm{L}$ ( $11.5 \mathrm{~g} / \mathrm{dL}$ ).

"Numbers do not add up to the column total due to missing data; percentages do add up to $100 \%$. Missing ethnic group $n=4, B M I n=3$, height for age $n=1$.

**Body mass index according to WHO standards.

Abbreviations: $\mathrm{BMI}$, body mass index; $\mathrm{Cl}$, confidence interval; $\mathrm{OR}$, odds ratio; $\mathrm{SD}$, standard deviation; WHO, World Health Organization.

age group. Girls had a slightly higher anemia prevalence (63.6\%) compared to boys (62.2\%). A total of $9.8 \%$ of the children were stunted (height for age $z$-score $\leq 2 \mathrm{SD}$ ).

In bivariable analysis, younger age and Maroon ethnicity were statistically significantly associated with anemia, $p<0.001$ and $p=0.001$, respectively; stunting (chronic malnutrition) was borderline significant, $p=0.05$. In multivariable analysis, the association between anemia and younger age remained significant, with very young children being more often anemic than older children (odds ratio $[\mathrm{OR}]=1.78 ; 95 \%$ CI: 1.27-2.51). Anemia was less prevalent in Amerindian than in Maroon children (OR=0.51; 95\% CI: 0.34-0.76). Hemoglobin level was not influenced by nutritional status, including BMI $\leq 2 \mathrm{SD}(\mathrm{OR}=0.63$; 95\% CI: $0.36-1.10)$ and chronic malnutrition, height for age $z$-score $\leq 2 \mathrm{SD}(\mathrm{OR}=1.83$ 95\% CI 1.00-3.38), nor by sex (OR=1.06; 95\% CI: 0.76-1.47 for females compared to males). Within the Maroon community, urbanization had no significant effect on hemoglobin level $p=0.85$ (OR=0.96; 95\% CI 0.66-1.41).

\section{Discussion}

The prevalence rate of anemia in children aged 1-5 years living in the three studied interior regions of Suriname is high $(63 \%)$ and exceeds the rates of similarly aged children in other Latin American countries and the Caribbean (range $4-45 \%) .{ }^{10}$

Anemia was more prevalent in children $1-3$ years of age, indicating that age is an important determinant for anemia. The high anemia prevalence in these very young children is alarming because of its expected negative impact on their ability to combat infections, whereas in the long term it could result in short stature, poor school performance and a lower capacity for physical work. ${ }^{11}$ Potential contributing factors could be the high prevalence of iron deficiency observed in pregnant women (Medical Mission, unpublished data, 2016), which may affect the development of limited fetal iron stores. ${ }^{12,13}$ Second, children in the interior are often solely breastfed and the amount of iron secreted in breast milk may not be sufficient to cover the infant's daily iron requirements. Third, weaning foods used during the transition period to the readily used diet in Suriname's interior are often low caloric and lack multiple micronutrients, especially iron. ${ }^{14}$

Maroon children were more affected compared to Amerindian children indicating that ethnic differences play a role in the occurrence of anemia in children living in Suriname's interior. These differences may partly be the result of genetic predisposition, but cultural differences and feeding practices may also be of influence. ${ }^{15,16}$

The prevalence of anemia was not influenced by BMI nor by chronic malnutrition. Anthropometric measurements to assess growth and development are the most widely used indicators of nutritional status, particularly in young children. However, anthropometric measurements are not sufficient to 
define nutritional status because dietary intake in children may meet daily caloric requirements but can be specifically deficient in micronutrients. This was also reflected in our study where over half of the normal and overweight children were anemic.

\section{Conclusion}

The prevalence of anemia in children aged 1-5 years living in the Suriname's interior is high, and younger children and children of Maroon descent are more often affected. Nutritional status, sex and region were not of influence on hemoglobin level. Further studies are necessary to investigate underlying causes in order to adapt anemia prevention and control programs reaching women of childbearing age and implement targeted interventions for young children.

\section{Acknowledgments}

The authors sincerely thank the Medical Mission health care workers who assisted so generously in this study. This work was supported by the Diplomatic and Consular Group Suriname. The abstract of this paper was presented at the $61 \mathrm{st}$ Annual Carpha Health Research Conference, June 23-25, 2016 as an oral presentation with interim findings. The presentation's abstract was published in "Poster Abstracts" in Western Indian Medical Journal, Vol. 65 (Suppl 3) 1-79: http://conference.carpha.org/Portals/0/docs/CARPHAHealth-Research-Conference-Supplement-2016-.pdf.

\section{Disclosure}

The authors report no conflicts of interest in this work.

\section{References}

1. World Health Organization. The Global Prevalence of Anaemia in 2011. Geneva: World Health Organization; 2015.

2. Gao W, Yan H, Wang D, et al. Severity of anaemia among children under 36 months old in rural western China. PLoS One. 2013;23:e62883.
3. De Benoist B, McLean E, Egli I, et al. Worldwide Prevalence of Anemia 1993-2005: WHO Global Database on Anemia. Geneva: World Health Organization; 2008.

4. Balarajan Y, Ramakrishnan U, Ozaltin E, Shankar AH, Subramanian SV. Anaemia in low-income and middle-income countries. Lancet. 2011;378: 2123-2135.

5. Sayed NE, Gad A, Nofal L, et al. Assessment of the prevalence and potential determinants of nutritional anemia in Upper Egypt. Food Nutr Bull. 1999;20:417-421.

6. World Health Organization. Suriname-Prevalence of Anaemia among Children. Geneva: World Health Organization; 2014.

7. World Health Organization [webpage on the Internet]. WHO Child Growth Standards: Length/Height-for-Age, Weight-for-Age, Weightfor-Length, Weight-for-Height and Body Mass Index-for-Age: Methods and Development. Geneva: World Health Organization; 2006:139-300. Available from: http://www.who.int/childgrowth/publications/en. Accessed January 12, 2017.

8. World Health Organization [webpage on the Internet]. WHO Child Growth Standards: WHO Anthro (Version 3.2.2) and Macros for SPSS. Geneva: World Health Organization; 2011. Available from: http://www. who.int/childgrowth/software/en/. Accessed January 12, 2017.

9. World Health Organization. Haemoglobin Concentrations for the Diagnosis of Anaemia and Assessment of Severity. Geneva: World Health Organization; 2011.

10. Mujica-Coopman M, Brito A, Lopez de Romana D, et al. Prevalence of anemia in Latin America and the Caribbean. Food Nutr Bull. 2015; (2 Suppl):S119-S128.

11. Low M, Farrell A, Biggs BA, Pasricha SR. Effects of daily iron supplementation in primary-school-aged children: systematic review and meta-analysis of randomized controlled trials. CMAJ. 2013;185(17): E791-E802.

12. Chang S, Zeng L, Brouwer ID, Kok FJ, Yan H. Effect of iron deficiency anemia in pregnancy on child mental development in rural China. Pediatrics. 2013;131(3):755-763.

13. de Sá SA, Willner E, Duraes Pereira TA, de Souza VR, Teles Boaventura G, Blondet de Azeredo V. Anemia in pregnancy: impact on weight and in the development of anemia in newborn. Nutr Hosp. 2015;32(5):2071-2079.

14. Van der Crabben SN, Heymans HS, van Kempen AA, et al. Qualitative malnutrition due to incorrect complementary feeding in Bush Negro children in Suriname. Ned Tijdschr Geneeskd. 2004;148(22): 1093-1097.

15. Brotanek JM, Halterman JS, Auinger P, Flores G, Weitzman M. Iron deficiency, prolonged bottle-feeding, and racial/ethnic disparities in young children. Arch Pediatr Adolesc Med. 2005;159(11):1038-1042.

16. Brotanek JM, Gosz J, Weitzman M, Flores G. Iron deficiency in early childhood in the United States: risk factors and racial/ethnic disparities. Pediatrics. 2007;120(3):568-575.
Research and Reports in Tropical Medicine

\section{Publish your work in this journal}

Research and Reports in Tropical Medicine is an international, peerreviewed, open access journal publishing original research, case reports, editorials, reviews and commentaries on all areas of tropical medicine, including: Diseases and medicine in tropical regions; Entomology; Epidemiology; Health economics issues; Infectious disease; Laboratory

\section{Dovepress}

science and new technology in tropical medicine; Parasitology; Public health medicine/health care policy in tropical regions; and Microbiology. The manuscript management system is completely online and includes a very quick and fair peer-review system. Visit http://www.dovepress. com/testimonials.php to read real quotes from published authors. 